\title{
Breve panorama histórico da formação de intérpretes no mundo e no Brasil e a influência da AIIC
}

Denise de Vasconcelos Araujo*

Neste artigo serão explicitados os laços entre a AIIC e a história da formação de intérpretes, enumerando e discutindo as melhores práticas da AIIC para formação de intérpretes e as evidências da profissionalização da formação de intérpretes nos últimos 20 anos, usando como exemplo a CIUTI e o EMCI na Europa ${ }^{1}$.

\section{A formação de intérpretes: os primórdios}

Como afirma Pöchhacker (2004, p.28), apesar de sempre terem existido intérpretes atuando profissionalmente, a atividade da interpretação começou a ser tratada como carreira profissional somente a partir do início do século $\mathrm{XX}$, com a formação de linguistas e tradutores. Pöchhacker atesta que a primeira escola dedicada à formação de intérpretes de conferência (naquela época, para a modalidade consecutiva apenas) foi o Institut fur Ubersetzen und

\footnotetext{
* Denise de Vasconcelos Araujo é mestre em Estudos da Linguagem pela PUC-Rio, professora do curso de Formação de Intérpretes da PUC-Rio e membro do Comitê de Formação e Atualização Profissional da AIIC.

${ }^{1} \mathrm{O}$ texto é um excerto adaptado do terceiro capítulo da dissertação de mestrado intitulada "Os cursos de formação de intérpretes no Brasil e as melhores práticas da Associação Internacional de Intérpretes de Conferência: um caminho para a profissionalização", escrita pela autora e defendida em 2017.
} 
Dolmetschen, baseado originalmente em Mannheim e coordenado por Antoine Velleman, intérprete da Liga das Nações.

A proliferação dos cursos de interpretação e tradução, ou só de interpretação, estava relacionada ao final dos anos 1920 e início da década de 1930 a Liga das Nações deu origem à Organização das Nações Unidas. No mesmo período começaram as atividades da CECA, Comunidade Europeia do Carvão e Aço, em toda a Europa, fazendo com que a presença de intérpretes fosse indispensável para que a comunicação entre os delegados de diferentes países se tornasse possível (Pagura, 2010a, p.11). As organizações precursoras da União Europeia trabalhavam com holandês, francês, alemão e italiano, enquanto o Conselho Europeu e a OTAN, com apenas dois idiomas (Mackintosh, 1999, p.69).

Após a Segunda Guerra Mundial foram realizados os julgamentos de Nuremberg, onde foram processados os oficiais do partido nazista. O tribunal para julgar os réus deveria ser formado por juízes da França, Reino Unido, União Soviética e Estados Unidos, tornando necessário o uso do serviço de interpretação. Até aquele momento a modalidade mais conhecida era a interpretação consecutiva. Contudo, se os julgamentos acontecessem em nessa modalidade os julgamentos demorariam muito mais tempo (Baigorri-Jalón, 2014, p.213). Sendo assim, decidiu-se testar a interpretação simultânea, modalidade até então pouco conhecida, que permite que a interpretação seja realizada ao mesmo tempo, feita pelos intérpretes em cabines e transmitida aos ouvintes através de receptores Os equipamentos foram fornecidos pela IBM, e quem coordenou o projeto foi o Coronel Léon Dostert, intérprete do exército americano (Baigorri-Jalón, 2014, p.219).

Até os julgamentos de Nuremberg, apesar de já existir a prática da interpretação simultânea, a modalidade ainda era muito malvista. Falando a respeito dos intérpretes de conferência atuantes no período antecedente aos julgamentos, Jesus Baigorri-Jalón (2014) diz: 
Curiosamente os intérpretes eram mais resistentes que os juristas (...). Por um lado, esses intérpretes [consecutivos] não gostavam da ideia de ficarem relegados ao anonimato da cabine, e por outro lado, a velocidade que a simultânea exigia representava um desafio que não queriam enfrentar². (p.215)

Na década de 1940 o ensino da técnica sequer fazia parte dos currículos das poucas escolas de interpretação existentes. A partir de Nuremberg e do bom funcionamento da modalidade, a simultânea passou a ser cada vez mais utilizada:

Portanto, antes mesmo que o veredito final fosse emitido em Nuremberg, o sistema já estava sendo testado nas Nações Unidas, em Nova Iorque. Em poucos anos, a simultânea se tornou a modalidade de interpretação predominante em conferências e organizações internacionais e permanece assim até hoje ${ }^{3}$. (Baigorri-Jalón, 2014, p.212)

Sendo assim, as escolas de formação de intérpretes tiveram que começar a incluir a interpretação simultânea no currículo, pois esta era a necessidade do mercado (Pöchhacker, 2004, p.28). A informação de Pöchhacker a respeito da necessidade de inclusão da simultânea nos currículos das escolas de interpretação da época é uma das poucas às quais é possível ter acesso. Pode-se inferir que as escolas formavam intérpretes para trabalhar no recémnascido mercado institucional europeu, mas não é possível determinar se a proposta pedagógica ou elementos curriculares eram semelhantes aos de hoje. Também não foi possível acessar o conceito de interpretação ou a visão do intérprete profissional que essas escolas tinham. Ainda assim, para situar o

\footnotetext{
${ }^{2}$ Curiously, the interpreters themselves were more resistant than the jurists...On the one hand these [consecutive] interpreters did not like the idea of being relegated to the anonymity of the booth, and on the other hand, the speed required by simultaneous struck them as a challenge they did not want to face.

3 Thus, even before the final verdict was issued at Nuremberg, the system was already being tried out at the United Nations in New York. Within a few years, simultaneous became the predominant mode of interpretation at international conferences and organizations, and it remains so today.
} 
leitor no contexto, relacionamos aqui as datas de fundação dos cursos pioneiros na Europa e nos Estados Unidos.

Na década de 1940 foram surgindo diferentes escolas de interpretação na Europa. Pagura (2010b, p.12) destaca uma em Genebra (1941), outra em Viena (1943), uma em Germersheim (1947), a escola de Saarbrucken (1948) e uma escola patrocinada pela HEC - École de Hautes Etudes Commerciales, fundada em Paris em 1948. Mackintosh (1999, p.69) menciona uma escola em Graz, fundada em 1947. A Universidade de Heidelberg recebeu, na década de 1950, a escola de Mannheim (Sawyer, 2003, p.20). Nos Estados Unidos, em 1949, foi fundado o curso de intérpretes na Universidade de Georgetown por Léon Dostert, responsável pelos serviços de interpretação em Nuremberg (Mackintosh, 1999, p.69).

A ESIT - École Supérieure d'Interprètes et de Traducteurs, uma das escolas de interpretação de maior prestígio na Europa, foi fundada em 1958, e o ISIT - Institut Supérieur d'Interprétation et de Traduction, em 1959. No final da década de 1950, Pilley fundou um curso de formação de intérpretes no Linguist's Club em Londres. A escola da Polytechnic of Central London (atual Westminster) foi fundada por Patricia Longley em 1963. O segundo curso a ser fundado nos Estados Unidos foi o curso do Monterey Institute of Foreign Studies (cujo nome atual é Middlebury Institute of International Studies, MIIS), em 1969 (ver Mackintosh, 1999, p.69).

Muito embora já houvesse conferências no Brasil desde antes deste período, o início da profissão no país está ligado às décadas de 1940 e 1950, quando começaram a ser organizados alguns congressos internacionais de maior destaque. A partir do levantamento histórico feito por Reynaldo Pagura (2010a) em sua tese A interpretação de conferências no Brasil: história de sua prática profissional e a formação de intérpretes brasileiros, é possível depreender duas maneiras de se tornar intérprete nesse período.

A primeira era buscar formação fora do país nas décadas de 1950 a 1970 e voltar para tentar trabalhar no Brasil. Pagura relata em seu texto o caso de alguns desses profissionais e chega à conclusão de que as intérpretes formadas 
fora tiveram dificuldades para se estabelecer no mercado do Rio de Janeiro por conta dos profissionais que já atuavam aqui. Esse impedimento na verdade produziu excelentes frutos. Fez com que essas intérpretes criassem suas próprias equipes, investissem na formação de novatos e abrissem o mercado de São Paulo e do Rio de Janeiro. Essas mesmas intérpretes (Ulla Schneider, Jaqueline Branco e Cecilia Assumpção) fundaram em 1971, com mais cinco colegas, a APIC, que hoje é a Associação Profissional de Intérpretes de Conferência (Pagura, 2010a, p.82).

A segunda maneira de se tornar intérprete naquele período diz respeito àqueles formados on the job, quase que por acaso, e "descobertos" quando colocados em situações de necessidade. Reynaldo Pagura escreve sobre a situação emblemática de Ângela Levy. Uma das intérpretes mais antigas do Brasil, coordenadora e professora do curso da Associação Alumni (em São Paulo) durante décadas, Ângela experimentou um batismo de fogo na profissão. Era funcionária da União Cultural Brasil-Estados Unidos e foi chamada pelo cônsul norte-americano para atuar como intérprete no $1^{\mathrm{o}}$ Congresso Pan-Americano de Radiodifusão, no dia em que o evento começava. A entrevista concedida a Pagura chega a ser cômica, pois sem nenhum aviso, treinamento, formação, nada, Ângela iniciou sua carreira aprendendo a interpretar com o operador de som do evento onde estava:

\footnotetext{
Você vai usar isso aqui e me deu uns earphones tão pesados, mas tão pesados que o meu queixo caiu em cima da mesa e eu falei assim: "O que que isso? How do I go about it?" E ele disse: "I'll tell you. Listen: they start 'Ladies and gentlemen it's a pleasure to'... and you start the Portuguese, the first sentence of [...] the lecture". Foi essa a informação que eu tive, o curso. (Levy, apud Pagura, 2010a, p.77)
}

A partir do caso de Ângela Levy, é possível perceber como a formação de intérpretes estava sendo estabelecida no país. Uma intérprete que foi "formada" em alguns minutos pelo operador de som. Costuma-se usar a expressão em inglês sink or swim ("afunde ou nade") para se referir a como os 
intérpretes entravam na profissão nesse período. Se a pessoa tivesse um bom desempenho, tornava-se intérprete. Se o desempenho fosse ruim, entendiam que ela não havia nascido para isso.

Um pouco depois dessa experiência, Ângela se tornou uma das fundadoras do curso de intérpretes da Associação Alumni, o primeiro de São Paulo, que foi criado em 1970, ensinando interpretação e tradução, e o currículo foi montado de forma bem intuitiva pela própria Ângela (Pagura, 2010a, p.167).

O primeiro curso de intérpretes do Brasil, criado em 1968 e iniciado em 1969, foi o da PUC-Rio. Teve início como uma das habilitações (denominadas especializações durante esse período) do curso de Letras e, na época, fazia parte do Bacharelado em Letras com habilitação revisor-tradutor-intérprete(Martins, 2007, p.172). A partir de 1974, a habilitação passou a ser somente tradutor-intérprete e se manteve assim até 1976, quando duas habilitações passaram a ser oferecidas: tradutor-intérprete e tradutor. Em 1978, a habilitação tradutor-intérprete passou a se ocupar apenas da formação de intérpretes, ficando duas habilitações, uma para tradução e outra para interpretação (Martins, 2007, p.179). Ao longo dos anos, ajustando-se às necessidades do mercado e também por conta do conhecimento de novas concepções acerca da formação de intérpretes, o curso foi passando por diversos formatos: graduação, sequencial, até se tornar a pós-graduação lato sensu que é hoje.

Além desses dois, Pagura indica a fundação de alguns outros cursos ainda nas décadas de 1970 e 1980, fase que denominamos "os primórdios" neste panorama histórico. Houve um curso de interpretação criado em 1970 na Pontifícia Universidade Católica do Rio Grande do Sul, trabalhando com inglês e alemão, que durou até meados da década de 1970 (Pagura, 2010a, p.174). Um segundo curso no Rio Grande do Sul, na Universidade Federal, foi fundado em 1972 e continuou até meados da década de 1990, com formação de intérpretes com francês, inglês, alemão, espanhol e italiano (Pagura, 2010a, 
p.174). Também fundado em 1972, o curso da antiga Faculdade IberoAmericana funciona até hoje integrando o grupo educacional Anhanguera.

\section{O papel da AIIC e sua school policy na formação de intérpretes e na formação de formadores.}

Retornando agora ao papel da AIIC na história da formação de intérpretes, em um artigo no qual celebrava 50 anos trabalhando com a formação de intérpretes, Danica Seleskovitch (1999) explica a origem da chamada school policy da AIIC. Ela foi secretária executiva da AIIC de 1959 a 1963, período em que a school policy foi estabelecida. De acordo com Seleskovitch, assim que as escolas de interpretação começaram a se estabelecer na Europa, dada a necessidade de difundir o ensino da modalidade simultânea, os próprios intérpretes de conferência passaram a se envolver com o ensino da interpretação.

Através da revisão da literatura percebemos que não há dados muito concretos a respeito das escolas existentes na época. Pode-se deduzir que eram cursos universitários de Letras ou Linguística que começaram a ensinar interpretação. Muito provavelmente esses professores-intérpretes da AIIC não faziam parte do quadro permanente de docentes dessas escolas, mas ainda assim colaboravam com a formação da nova geração de intérpretes. Contudo, apesar dessa colaboração, a opinião dos intérpretes veteranos muitas vezes não era considerada na formação do currículo e nas avaliações finais (Seleskovitch, 1999, p.58).

Por conta disso os profissionais começaram discussões em suas assembleias para estabelecerem uma iniciativa a partir da Associação Internacional e, dessa maneira, fazer um esforço conjunto em prol da formação de novos intérpretes (Seleskovitch, 1999, p.58). Nascia o Comitê de Escolas da AIIC. O objetivo inicial do comitê era credenciar escolas que atendessem aos critérios estabelecidos pela associação como essenciais para a formação de intérpretes. 
De acordo com Seleskovitch, foram quatro as escolas que receberam o reconhecimento da AIIC a partir de 1963: Genebra, Heildelberg, Sorbonne e a HEC de Paris. A ideia de contribuir com a formação de intérpretes não era consenso entre os associados. Alguns deles acreditavam que a interpretação não podia ser ensinada, com base na máxima máxima: “intérpretes já nascem intérpretes" ${ }^{\prime \prime}$, por isso não se interessavam por essa cooperação com os cursos de interpretação (Seleskovitch, 1999, p.58).

Em artigo escrito sobre a formação de intérpretes de conferência, Jennifer Mackintosh (1999) aponta que, assim como a AIIC estabeleceu padrões profissionais bem específicos desde a sua fundação, também formulou critérios a partir dos quais os cursos de formação de intérpretes deveriam ser avaliados. Esses critérios, de acordo com Mackintosh, foram “defendidos em simpósios e workshops desde 1969 e já haviam aparecido em outras publicações. Hoje se tornaram o parâmetro que a profissão adota para avaliar os padrões de formação." ${ }^{5}$ (p.72).

Cabe esclarecer neste momento que, desde a fundação da AIIC, é no âmbito da associação que se reúnem os principais pesquisadores, formadores e profissionais da área. Danica Seleskovitch, Marianne Lederer, Daniel Gile, Barbara Moser-Mercer e David Sawyer, entre tantos outros, foram ou ainda são membros da associação. Desta maneira, seria impossível tratar da história da formação de intérpretes sem tratar da história da AIIC.

Os critérios que devem ser atendidos são: que o curso seja ministrado em nível de pós-graduação; que um teste de aptidão seja realizado antes do início do curso (para programas de até um ano) ou no início das aulas no caso de cursos mais longos; na medida em que as disciplinas são predominantemente voltadas para a prática, que os professores do curso sejam intérpretes de conferência; que a grade curricular inclua tanto interpretação

\footnotetext{
4 Em inglês,"interpreters are born, not made".

${ }^{5}$ advocated in symposia and workshops from 1969 onwards which already appeared in earlier publications. Now they officially became the yardstick by which the profession rated training standards.
} 
consecutiva quanto simultânea; e que a duração do curso seja de no mínimo dois semestres (um ano letivo).

Atualmente a AIIC não credencia mais escolas como fazia inicialmente. O comitê de escolas, que hoje chama-se Comitê de Formação e Atualização Profissional ${ }^{6}$, é o órgão da associação que tem a responsabilidade de publicar uma lista das escolas que atendem os requisitos da AIIC para a formação. Além disso, organiza cursos de desenvolvimento e atualização profissional e formação de formadores (Vianna, 2017 p.5). A lista, chamada AIIC Interpreting Schools and Programme Directory ${ }^{7}$, inclui 86 escolas de interpretação no mundo todo e é atualizada à medida que os cursos enviam seus dados e estes são verificados pelo comitê. Não há uma frequência média de atualização da lista.

Branca Vianna (2017), que foi membro do Comitê de Formação da AIIC, descreve o processo para que o curso seja incluído na listagem:

Os cursos interessados em participar do cadastro respondem a quase quarenta perguntas sobre currículo, corpo docente, uso de tecnologia, combinações linguísticas, exames de aptidão e finais, número de diplomas conferidos versus número de candidatos aceitos e muitas outras. (Vianna, 2017, p.5)

A exigência mínima é que atendam aos seis critérios descritos nos parágrafos acima e enviem seus dados. Na América Latina só há dois cursos que estão incluídos no diretório. E ambos são do Brasil. ${ }^{8}$

É necessário esclarecer que duas das recomendações abrem bastante espaço para questionamento. A primeira é sobre o nível de pós-graduação. Em nenhum momento a AIIC faz distinção entre diferentes tipos de pós-graduação stricto sensu como mestrado e doutorado, que tendem a se concentrar mais em pesquisa, e os cursos de pós-graduação lato sensu que, apesar de também envolverem pesquisa, possuem uma ênfase maior no aspecto profissionalizante. Por existir um outro critério determinando que os

\footnotetext{
${ }^{6}$ AIIC Training and Professional Development.

${ }^{7}$ http://aiic.net/directories/schools/ acessado em 5 jun. 2018.

${ }^{8}$ São os cursos da PUC-Rio e PUC-SP.
} 
professores dos cursos sejam intérpretes, pode-se inferir que o perfil dos cursos seja mais profissionalizante mas, ainda assim, não é possível definir com certeza.

Além dessa recomendação, há outra que afirma que o curso deve ter pelo menos dois semestres de duração. Não há menção a exigências de carga horária. Isso poderia sugerir que há uma preocupação com o tempo cronológico mínimo de um ano, o que talvez seria importante para desenvolver melhor as habilidades necessárias para a prática da interpretação. Contudo, a recomendação pode também abarcar programas com a duração de um ano, mas com uma carga horária muito reduzida, como apenas duas horas por semana durante dois semestres.

O documento denominado AIIC School Survey ${ }^{9}$ elenca as melhores práticas para a formação de intérpretes. Além dos seis itens principais mencionados acima, há outras recomendações. A respeito dos professores, além de serem intérpretes de conferência, recomenda-se que atuem no mercado e possuam formação específica para serem formadores. Isso para as disciplinas de interpretação. $\mathrm{O}$ documento não menciona recomendações quanto a disciplinas que não sejam de prática ou teoria da interpretação, como as relacionadas ao cuidado com a voz, ensino de pesquisa específica para preparação de conferências, metodologia da pesquisa, entre outras.

Além disso, recomenda-se que os professores sejam falantes nativos de um dos idiomas da combinação linguística oferecida pelo curso e, preferencialmente, ter uma combinação linguística reconhecida pela AIIC. Quanto aos candidatos, a recomendação é que, para desenvolverem um nível adequado de competência linguística, devem ter residido por "um período considerável" nos países que falam os idiomas de sua combinação linguística.

A respeito da conexão dos alunos com o mercado, as recomendações são de que a escola informe durante e após o curso quanto às oportunidades de trabalho. As escolas de interpretação também devem ter uma disciplina que

\footnotetext{
${ }^{9}$ https://aiic.net/page/3420/aiic-s-survey-of-interpreting-schools-and-programmes Acesso em 14 mar. 2017
} 
ensine a respeito de prática profissional e ética. Além disso, é recomendado que o curso possua um componente teórico.

Em relação à avaliação final, o texto da AIIC cobre vários aspectos, começando por dizer que os critérios e a condução da avaliação devem ser abertos e transparentes. O candidato deve ser avaliado tanto em simultânea quanto consecutiva, em todas as suas línguas de trabalho, e estas devem estar listadas em seu certificado. A banca de avaliação deve ser composta pelo corpo docente e avaliadores externos que sejam intérpretes de conferência atuantes. Também devem ser convidados representantes de organizações internacionais e outras instituições que contratam intérpretes, para participar das avaliações como observadores.

Um ponto interessante nas recomendações afirma que as instituições não podem se beneficiar financeiramente de trabalhos feitos por seus alunos.

Vemos que Mackintosh (1999) comenta que, a partir destes critérios, podem-se perceber questões que não representam um consenso na formação de intérpretes de conferência:

A formação em interpretação de conferências deve ser sempre em nível de pós-graduação? A interpretação de conferências pode ser ensinada por pessoas que não sejam intérpretes profissionais? Os cursos devem refletir as exigências do mercado? Outras questões que não são consenso: o ensino de idiomas deve ser incluído de alguma forma nos cursos de formação de IC? Em que momento durante o programa do curso deve ser iniciada a formação em interpretação simultânea? Deve-se ensinar teoria durante a formação? Se sim, qual teoria? Qual é a duração ideal de um curso? (p.72) ${ }^{10}$

Julie Boéri (2015), professora de interpretação na Universidade Pompeu Fabra em Barcelona, em uma apresentação crítica desta influência exercida pela AIIC na formação de intérpretes, sugere que a atuação do Comitê de

\footnotetext{
10 Should all CI training be postgraduate? Can CI be taught by persons who are not professional interpreters? Should courses be matched to market requirements? Other contentious issues include: does language teaching have any place in a CI training course? At what point in a programme should training in simultaneous commence? The place in theory in CI training, and if so, which theory? What is the optimum course duration?
} 
escolas foi uma das ações da AIIC que auxiliou a entidade a se tornar tão influente entre os profissionais como um todo. No capítulo "Key internal players in the development of the interpreting profession", em The Routledge Handbook on Interpreting, a autora indica o papel da AIIC em três áreas: o contato direto com contratantes de serviços de interpretação, a subscrição ao código de ética da associação como forma de controle dos seus membros e o lobby junto às escolas de interpretação.

Boéri destaca que, quando foi estabelecida, a chamada school policy da AIIC era uma forma de instruir todos os que estivessem envolvidos com formação de intérpretes a respeito do que era uma formação adequada para conseguir o reconhecimento da associação (Boéri, 2015, p.33). Havia uma lista de critérios a serem seguidos para que a instituição tivesse seu nome citado como escola recomendada pela AIIC (na época em que foram criados). Apesar de hoje essas recomendações não constituírem a função normativa que já tiveram, para Boéri esse foi um dos fatores que fortaleceu a associação, pois a AIIC estava diretamente envolvida, controlando, de certa forma, a formação dos futuros membros.

Em seu artigo "O consenso internacional sobre a formação de intérpretes de conferência" (2010b), o professor Reynaldo Pagura endossa as melhores práticas da AIIC, que podem ser vistas em praticamente todo o consenso internacional discutido por ele. Pagura nomeia cinco questões principais como constituindo o consenso internacional na formação de intérpretes. Três delas são corroboradas pelas melhores práticas da AIIC e duas estão relacionadas a questões metodológicas.

As questões metodológicas dizem respeito a quando a interpretação simultânea deve ser ensinada e ao ambiente adequado para ministrar aulas de interpretação. Pagura (2010b), em consonância com a visão da Théorie du sens, de que é importante ensinar os futuros intérpretes a se apegarem cada vez mais ao sentido da mensagem para aprenderem a técnica da interpretação, defende que a consecutiva deve preceder a simultânea no currículo. Essa de fato é a prática em muitas escolas na Europa, inclusive algumas delas só 
permitem que o aluno inicie aulas em simultânea tendo sido aprovado em consecutiva (Pagura, 2010b, p.21).

A respeito do ambiente ideal para as aulas, Pagura se opõe à prática de alguns cursos de ministrar aulas de interpretação em laboratórios para ensino de idiomas, onde os alunos são dispostos em baias. Ele alega que, nessa situação, o professor não consegue monitorar adequadamente a turma, além de não ser possível trabalhar em duplas. Ademais, os fones de ouvido utilizados nesses laboratórios não possibilitam aos alunos se ouvirem enquanto interpretam e, portanto, se automonitorarem. (Pagura, 2010b, p.24).

Os laboratórios de idiomas que usamos hoje, por mais recursos que possuam, podem acabar restringindo as atividades feitas em classe. Resumindo o que acredita ser essencial para o ambiente de formação de intérpretes, Pagura (2010b) declara:

Não é, pois, o número de cabines que faz a diferença em um curso de interpretação, servindo tal fato apenas como apelo comercial aos leigos. O que importa, de fato, é seu uso adequado, num processo de formação com a progressão que leve os alunos a desenvolverem as técnicas que os tornarão verdadeiros intérpretes de conferência ( p.24).

Um outro ponto destacado por Pagura é o de que somente candidatos com maturidade intelectual e comprovada competência linguística devem ser aceitos nos cursos. O autor cita Namy:

Não se trata de atribuir virtudes mágicas aos títulos universitários; vemos neles, simplesmente, a garantia de um mínimo de maturidade intelectual, de discernimento, de gosto pelos estudos. Buscamos os candidatos "de cabeça feita" [...] É preciso acrescentar que eles deverão se submeter a uma seleção rigorosa, especialmente no que concerne ao conhecimento de línguas passivas, que devem compreender e falar sem dificuldade (Namy, 1988, apud Pagura, 2010b, p.45)

Essa afirmação está relacionada a dois critérios das recomendações AIIC: o fato de que os cursos devem ser de pós-graduação e a importância dos 
testes de aptidão para o acesso aos cursos. Pagura também elabora sobre outras duas questões relacionadas aos critérios recomendados pela AIIC: aborda a recomendação de que os cursos devem possuir pelo menos um ou dois anos acadêmicos e apoia a premissa de que os docentes precisam ser intérpretes. Como mencionado anteriormente, a AIIC recomenda que os professores sejam intérpretes atuantes no mercado e que se mantenham capacitados através de cursos para formação de formadores.

Seleskovitch (1999) sustenta que a AIIC acertou ao definir que os professores devem ser intérpretes de conferência, pois isso reflete o consenso entre os profissionais (. "Entre intérpretes há um fortíssimo entendimento de que a formação deve ser responsabilidade de intérpretes em atividade" $(\text { p.59) })^{11}$. Para a autora,

Os intérpretes sabem o que querem alcançar com o ensino e sabem como fazêlo. Conseguem selecionar materiais bons para a formação, sabem como corrigir erros metodológicos e podem demonstrar através de seu próprio desempenho o modelo que os alunos devem seguir. ${ }^{12}$ (p.60)

Sobre formação de formadores, Seleskovitch (1999) comenta que:

Formadores em potencial devem ser, em primeiro lugar, intérpretes altamente qualificados. Além do know-how, devem ter o know-why, a capacidade de diagnosticar os porquês. Devem não somente perceber os erros e problemas de interpretacão, mas também detectar os motivos desses erros e colocar os alunos no caminho certo. ${ }^{13}$ (p.65)

\footnotetext{
${ }^{11}$ Among interpreters there is an overwhelming agreement that training should be the sole responsibility of practicing interpreters.

12 Interpreters know what their teaching is aiming to achieve and how to achieve it. They know how to select speeches for training, how to correct methodological errors and last but not least they are able to offer students their own performance as a model to be followed.

${ }^{13}$ Prospective teachers should first of all be highly qualified interpreters. In addition to know-how, 'knowwhy' is required to be a good teacher. They should also be able not only to note mistakes and misinterpretations but also to detect the reasons of such errors and put their students on the right track.
} 
Essas duas afirmações confirmam que o "professor intérprete" não precisa necessariamente ser um profissional atuante no mercado e ainda assim ministrar aulas no curso. Pode ser um intérprete aposentado ou que decidiu dedicar-se exclusivamente à docência por um período. Entretanto, não seria recomendado ter um "professor intérprete" que possua formação em interpretação sem ter tido vivência ou experiência no mercado, pois isso invalidaria sua posição como alguém que pode modelar e demonstrar estratégias para os alunos.

Em seu artigo sobre a formação de intérpretes, Jennifer Mackintosh (1999) aborda o período de transição que a interpretação de conferências experimentou. Inicialmente a atividade era vista como uma ocupação que as pessoas "nasciam prontas" para exercer. Hoje é percebida pelas pessoas envolvidas com interpretação como uma profissão onde a formação é indispensável (p.67). Ela fala, no texto, dos aspectos relacionados à importância de uma formação de qualidade e realizada em nível profissional.

Mackintosh faz menção a um simpósio da AIIC em 1965 em Paris, que teve como tema o ensino da interpretação de conferências. A discussão no evento se deu em torno do currículo dos cursos, testes de aptidão, combinação linguística e nível de habilidade linguística, conteúdo das disciplinas, metodologia de ensino, em que momento da formação iniciar o ensino da interpretação simultânea. Mackintosh registra, assim como Pöchhacker (2004), que a partir da década de 1970, estendendo-se até a de 1990, o foco da pesquisa nos Estudos da Interpretação mudou, e o que entrou em voga foram os modelos baseados na teoria de processamento da informação e na linguística. Mas, já que muitos intérpretes e pesquisadores interessados nessas teorias estavam envolvidos com o ensino, elas começaram a influenciar o currículo de formação de intérpretes de conferência .

A respeito do ensino da teoria de interpretação durante a formação, Mackintosh (1999) faz duas contribuições pertinentes. Hoje, em 2018, parece óbvio que os futuros intérpretes devam ser iniciados nos Estudos da Interpretação e que a teoria precisa fazer parte do currículo dos cursos, mesmo 
que não haja uma disciplina específica com esse nome. A autora esclarece que no início havia resistência ao ensino da teoria por parte dos formadores, por dois motivos: uns ainda acreditavam que os intérpretes nasciam intérpretes, portanto não haveria motivo para ensinar teoria da interpretação. Outros, por estarem tão envolvidos com o seu trabalho como intérpretes e como professores, tinham pouco tempo para estudar e não se interessavam por questões teóricas. Além disso, percebiam que, apesar de não haver um componente teórico presente na formação, seus alunos se formavam com um excelente desempenho em cabine (Mackintosh, 1999, p.73).

A outra contribuição de Mackintosh é que, apesar de não ser possível comprovar que o ensino de teoria de fato beneficie os futuros profissionais, pode-se concluir que à medida que forem adquirindo mais conhecimento a respeito de ferramentas teóricas que os ajudem a enfrentar momentos difíceis e adquirindo mais consciência a respeito dos processos existentes na interpretação, os alunos terão um desempenho cada vez melhor (Mackintosh, 1999, p.74).

A primeira organização a oferecer oportunidades de formação para formadores de intérpretes de conferência de forma ampla foi a própria AIIC, através do seu Comitê de Formação e Atualização Profissional ${ }^{14}$, em janeiro de 1991. Mackintosh relata:

Foi o primeiro evento do tipo e ficou superlotado. Ficou evidente que muitos formadores de intérpretes sentiam necessidade de comparar suas experiências e práticas em sala de aula com outros formadores e de ouvir quais soluções foram encontradas [...](1999, p.75) ${ }^{15}$

O workshop promovido pela AIIC alguns anos depois passou a ser chamado de Training of Trainers (ToTs), um seminário curto, com duração de 2

\footnotetext{
${ }^{14}$ Nessa época ainda chamado de Training Committee em inglês.

${ }^{15}$ It was the first such event of its kind and was over-subscribed. It was evident that many interpreter trainers felt the need to compare their experience and classroom practice with others and to hear what solutions had been found [...]
} 
a 3 dias, onde se ensina um assunto específico pertinente à formação de formadores. Os ToTs são ministrados por intérpretes que são formadores experientes no assunto que vão ensinar.

Até hoje, só três organizações no mundo oferecem oportunidades de formação para formadores de intérpretes: a AIIC, a Faculdade de Tradução e Interpretação da Universidade de Genebra e a Divisão de Interpretação da Comissão Europeia (Vianna, 2017). Dentre essas três, a única que oferece uma formação em período extenso é a Universidade de Genebra. O programa do mestrado em formação de formadores (Certificate, Diploma and Master of Advanced Studies in Interpreter Training), é realizado à distância e composto por doze módulos, com duração de 2 anos no total.

A Divisão de Interpretação da Comissão Europeia só forma instrutores para seus próprios cursos. Já a AIIC, apesar de não possuir um curso com período extenso para a formação de formadores, oferece seus ToTs em diversos países do mundo, multiplicando o conhecimento para formadores que sejam membros ou não da associação. Pela falta de oportunidades formais, a maior parte dos formadores tem que gerenciar sua própria formação. É preciso dedicar-se à leitura de livros e artigos, manter-se atualizado indo a congressos e conferências, interagir com outros docentes e buscar cursos avulsos. Os ToTs da AIIC são uma maneira de preencher essa lacuna que os formadores possuem em sua capacitação profissional com especialistas em diferentes áreas.

A respeito da importância da formação profissional, formação de formadores e mais resultados de pesquisa, Mackintosh já apontava em 1999 o que ainda é extremamente necessário hoje em dia:

Para que a pedagogia de interpretação de conferências contribua de forma eficaz com a formação de intérpretes no século 21, não só terá que se concentrar mais na formação de formadores, mas também terá que fazer uso sistemático de resultados de pesquisa em diversas áreas como, por exemplo, as melhores estratégias para pares linguísticos específicos (especialmente línguas que possuam estruturas diferentes), a natureza e os efeitos da carga de processamento na compreensão e produção de discurso na interpretação 
simultânea, comparação entre trabalhar para a língua B e para a língua A e, especificamente, a área de avaliação de desempenho, muito difícil e ainda muito pouco pesquisada. ${ }^{16}$ (Mackintosh, 1999, p.77)

\section{A formação de intérpretes nos últimos 20 anos}

O professor de interpretação Chuanyun Bao, do Middlebury Institute of International Studies, em um capítulo sobre o ensino de interpretação escrito em 2015, registra que, em 2005, havia no mundo 230 programas só para formação de intérpretes (Bao, 2015, p.400). Mira Kim já havia contado mais de 600 programas de formação de tradutores e intérpretes no mundo todo em 2013 (p.102). Comentando esses números de Kim, Bao salienta que essa mudança brusca, em apenas oito anos, mudou o cenário do ensino da interpretação (Bao, 2015, p.400).

De acordo com Bao, uma das questões que influenciou a mudança foi a profissionalização da formação, ou seja, a oferta de cursos de formação mais profissionais. Ele faz referência ao European Masters in Conference Interpreting (EMCI), um acordo feito em maio de 2001 para estabelecer um consórcio de 11 universidades na Europa que se utilizam das mesmas diretrizes para formar intérpretes. Atualmente os membros do EMCI estão na Bélgica, Eslovênia, Espanha, França, Hungria, Itália, Polônia, República Tcheca, Romênia, Suíça e Turquia. O consórcio trabalha em colaboração com a divisão de interpretação da Comissão Europeia e do Parlamento Europeu.

A importância do EMCI é que, apesar das instituições possuírem certa autonomia para terem seus próprios currículos, há diretrizes básicas relacionadas ao currículo acadêmico e ao processo de admissão e avaliação final que precisam ser cumpridas. Em relação ao currículo acadêmico, as instituições participantes concordam a respeito da necessidade de ensinar

\footnotetext{
${ }^{16}$ If CI pedagogy is to contribute effectively to training interpreters for the 21st century, not only will it have to focus much more closely on training the trainers but will also have to learn to make systematic use of research findings into areas as diverse as the strategies best suited to given language pairs (especially structurally distant languages); the nature and effects of the processing load incurred in speech comprehension and production in simultaneous interpretation; working into a B language as against an A language and, in particular, the difficult and seriously under-researched area of performance measurement.
} 
teoria da interpretação, a prática da interpretação (contendo disciplinas que auxiliem nessa área como oratória e comunicação, técnicas de preparação para conferências, etc.) e interpretação consecutiva e simultânea.

Em relação ao processo de admissão, deve haver um teste de aptidão e uma prova de conhecimentos gerais. A avaliação final deve ser realizada com banca, composta por intérpretes profissionais, formadores de intérpretes, um avaliador externo e um representante das instituições europeias. O certificado do EMCI só é concedido ao aluno se ele passar em todos os exames na combinação linguística desejada.

Essas diretrizes estabelecidas garantem consistência a respeito do tipo de formação oferecida pelas instituições (Bao, 2015, p.401). O site do EMCI revela que "os membros do Consórcio têm como objetivo contribuir com a disseminação de boas práticas na Europa". ${ }^{17}$ Algumas das universidades integrantes do EMCI também fazem parte da CIUTI, Conférence Internationale Permanente d'Instituts Universitaires de Traducteurs et Interprètes (Conferência Internacional Permanente de Institutos e Universidades de Tradução e Interpretação).

Franz Pöchhacker (2004), em seu livro Introducing Interpreting Studies, define a CIUTI, formada no início da década de 1960, como sendo um grupo seleto constituído por instituições formadoras de tradutores e intérpretes que desejavam observar os critérios descritos na school policy da AIIC, principalmente a defesa de que os cursos de formação de intérpretes fossemministrados por intérpretes de conferência que estivessem trabalhando no mercado (Pöchhacker, 2004, p.30-31). Atualmente a CIUTI é formada por 45 universidades em 19 países (Bao, 2015, p.404).

A função das duas instituições (CIUTI e EMCI) é distinta. A proposta da CIUTI é de associar instituições que ofereçam programas de mestrado em Tradução e Interpretação, promovendo melhores práticas nas áreas de formação e pesquisa, aumentando também a probabilidade de contratação de

17 the participants aim to contribute to spreading good practice across Europe. http://www.emcinterpreting.org/?q=node/11 Acesso em 5 jun. 2018. 
seus formandos. ${ }^{18}$ Ela coopera com a formação para formadores das instituições participantes, realiza fóruns anuais e concede um prêmio à melhor dissertação de mestrado defendida em uma das universidades associadas. A CIUTI também mantém contato direto com diversos empregadores de serviços de tradução e interpretação.

O EMCI, por sua vez, é um programa de mestrado praticamente conjunto, utilizando o mesmo certificado, oferecido por onze instituições diferentes. Os membros aceitam submeter sua grade curricular aos critérios estipulados pelo EMCI, conforme discriminado acima. Mesmo em se tratando de propostas diferentes, o objetivo de citar o EMCI e o CIUTI é demonstrar como essas iniciativas conjuntas têm como objetivo profissionalizar a formação de intérpretes, compartilhando as melhores práticas e aproximando as instituições que oferecem formação de qualidade na área.

Essas iniciativas de oferecer formação conjunta se tornaram exemplo para outros cursos de formação ao redor do mundo e revelam um nível mais alto de profissionalização da formação. Aqui no Brasil, apesar de termos um cenário diversificado, já estamos formando intérpretes há 48 anos e, aparentemente, a profissionalização se intensificou nos últimos 18 anos, fato percebido por vermos pelo menos nove cursos de formação fundados durante o período ${ }^{19}$.

Nos anos mais recentes, vimos o despontar do uso de redes sociais, sites e blogs no contexto da interpretação de conferência. Dois dos mais conhecidos blogs, A word in your year ${ }^{20}$ e The interpreter diaries ${ }^{21}$, são de formadores de intérpretes. A word in your year é gerenciado por Lourdes de Rioja, formadora de intérpretes na Universidade de La Laguna (Espanha). Em seu blog ela publica vídeos nos quais convida colegas para tratarem de

\footnotetext{
18 http://www.ciuti.org/about-us/questions-answers/ Acesso em 22 de março de 2016

19 Os dados aqui citados podem ser lidos com mais profundidade no capítulo 5 da dissertação, onde apresento um perfil de cada curso de formação de intérpretes participantes da pesquisa realizada.

${ }^{20}$ https://lourdesderioja.com/ Acesso em 14 mar. 2017

${ }^{21}$ https://theinterpreterdiaries.com/ Acesso em 14 mar. 2017
} 
diferentes assuntos, escreve textos sobre tópicos relevantes (entonação na interpretação, dicas para uso de tecnologia etc).

O blog The interpreter diaries é gerenciado por Michelle Hof, também professora de La Laguna e do Glendon College (Canadá). O conteúdo é predominantemente de textos que contêm dicas, depoimentos do mundo da interpretação e divulgação de cursos ou oportunidades para formadores.

Além dos blogs, temos as interações por grupos no Facebook. No Brasil há dois grupos de intérpretes profissionais. O mais antigo, Intérpretes de Conferência, já conseguiu cadastrar 781 membros $^{22}$. Outro mais recente, fundado em 2015, Intérpretes de Conferência Profissionais, possui 115 $\operatorname{membros}^{23}$. Além desses dois, há também um grupo chamado Intérpretes de Conferência Iniciantes (com 1.036 membros $^{24}$ ), que conta com estudantes e egressos recentes de cursos de interpretação. Toda essa interação tem certamente tornado as informações sobre a profissão mais acessíveis e aproximado os colegas. As interações são das mais diversas: dúvidas, textos sobre o reconhecimento da profissão e dos profissionais, posts sobre situações de trabalho e problemas com clientes, divulgação de eventos, etc.

As ofertas de formação de intérpretes aqui no Brasil nos últimos 20 anos também se intensificaram bastante. O primeiro curso a ser fundado nesse período foi o da PUC-SP (1999), seguido por mais dezessete cursos em diferentes formatos - cursos livres, sequenciais, de graduação, pós-graduação e até cursos totalmente online ${ }^{25}$.

\footnotetext{
${ }^{22}$ https://www.facebook.com/groups/interpretesdeconferencia/ Acesso em 14 maio de 2018.

${ }^{23}$ https://www.facebook.com/groups/1422171661441356/ Acesso em 14 maio de 2018.

24 https://www.facebook.com/groups/interpretesiniciantes/ Acesso em 14 maio de 2018.

${ }^{25}$ De acordo com o levantamento realizado pela autora na dissertação anteriormente mencionada, esses eram os cursos de formação de intérpretes de línguas orais-auditivas em funcionamento no Brasil em 2017: Anhanguera (antigo Unibero), Associação Alumni, Brasillis, Easy Translations, Estácio de Sá RJ e SP, Faculdade FIBRA (que possui dois programas distintos para formação de intérpretes - uma pós-graduação e um curso de graduação), FMU, Infoland, Interpret2b, PUC-Rio, PUC-SP, São Judas Universidade, Universidade Metodista de São Paulo, UNASP, Universidade Católica de Santos, Universidade de Franca, Unilago - União das Faculdades dos Grandes Lagos, Uninove, Versão Brasileira.
} 
Nessa última década estamos vivendo um novo momento no campo dos EI, com interesse renovado em pesquisas, motivadas pelo desejo de conhecer mais a respeito dos profissionais e também com a publicação das monografias dos cursos de formação de intérpretes em nível de pósgraduação. É um período de consolidação da profissionalização do campo em todos os aspectos, incluindo a formação de intérpretes. Concluímos com as palavras de Branca Vianna (2017):

\begin{abstract}
Reynaldo Pagura inaugura, em 2010, com sua tese sobre a história da interpretação no Brasil (Pagura, 2010), uma nova era em que intérpretes profissionais e estudantes começam a criar um banco de teses, dissertações, monografias, trabalhos de conclusão de cursos e apresentações em congressos. Empregando os recursos oferecidos pela mídia social e questionários on-line, começamos a descobrir quantos somos, quanto ganhamos, onde estamos, o que pensamos de nós mesmos, que idade temos, qual é a nossa formação, interesses, idiomas de trabalho. Esses dados, por enquanto soltos e coletados, em alguns casos, sem muito rigor acadêmico, começam a criar um princípio de identidade profissional, em torno da qual o grupo se torna potencialmente mais coeso e mais forte. (p.3)
\end{abstract}

\title{
Referências
}

AIIC School Survey. https://aiic.net/page/3420/aiic-s-survey-of-interpretingschools-and-programmes Acesso em 5 jun. 2018.

ARAUJO, Denise de Vasconcelos. Os cursos de formação de intérpretes no Brasil e as melhores práticas da Associação Internacional de Intérpretes de Conferência: um caminho para a profissionalização. Dissertação (Mestrado em Estudos da Linguagem). 2017. Pontifícia Universidade Católica do Rio de Janeiro, Departamento de Letras, Rio de Janeiro.

BAIGORRI-JALÓN, Jesús. From Paris to Nuremberg: The birth of conference interpreting. Amsterdam/Philadelphia: John Benjamins Publishing, 270p., 2014. 
BAO, Chuanyun. Pedagogy. In: Mikkelson, H. and Jourdenais, R. The Routledge Handbook of Interpreting. London and New York: Routledge. 2015, p. 400-416.

BOÉRI, Julie. In: Mikkelson, H. and Jourdenais, R. The Routledge Handbook of Interpreting. London and New York: Routledge. 2015, p. 29-44.

EMCI Interpreting. http://www.emcinterpreting.org/?q=node/11 Acesso em 5 jun. 2018.

KIM, Mira. Research on translation and interpreter education. The Routledge Handbook of Translation Studies. London and New York: Routledge. 2013, p. 102-116.

MACKINTOSH, Jennifer. Interpreters are made not born. Interpreting, Amsterdam/Philadelphia, Volume 4, Issue 1, 1999, p.67-80.

MARTINS, Marcia Amaral Peixoto. A institucionalização da tradução no Brasil: o caso da Puc-Rio.. Cadernos de Tradução, Florianópolis, v. 1, n. 19, set. 2007, p. 171-192,. Disponível em:

$<$ https://periodicos.ufsc.br/index.php/traducao/article/view/6997>. Acesso em: 5 junho. 2018. .

MAS in Interpreter Training. Universite de Geneve. www.unige.ch/fti/en/faculte/departements/dint/education/\#toc1 Acesso em 5 jun. 2018.

PAGURA, Reynaldo José. A Interpretação de Conferências no Brasil: história de sua prática profissional e a formação de intérpretes brasileiros. 2010a. Tese (Doutorado em Letras) - Faculdade de Filosofia, Letras e Ciências Humanas, Universidade de São Paulo, São Paulo.

O Consenso Internacional sobre a Formação de Intérpretes de Conferência. Tradução e Comunicação, v. 21, 2010b, p. 11-29.

PÖCHHACKER, Franz. Introducing interpreting studies. New York, NY: Routledge, 2004.

Portal CIUTI. http://www.ciuti.org/about-us/questions-answers/ Acesso em 5 jun. 2018. 
SELESKOVITCH, Danica. The Teaching of Conference Interpretation in the Course of the Last 50 Years. Interpreting, Amsterdam/Philadelphia, Volume 4, Issue 1, 1999, p.55-66.

VIANNA, Branca. A atuação do Comitê de Formação e Atualização Profissional da AIIC no novo panorama de ensino e pesquisa no Brasil. Publicações i2B. Tópicos e contextos em interpretação, vol. 2, 2017. Disponível em $<$ http://www.interpret2b.com/publicacoes $>$. Acesso em 5 jun.2018.

\section{Resumo}

Apesar da interpretação ser uma atividade profissional existente há séculos, pode-se dizer que a oferta de cursos de formação de intérpretes se estabeleceu a partir da primeira metade do século XX. Neste artigo serão explicitados os laços entre a Associação Internacional de Intérpretes de Conferências (AIIC) e a história da formação de intérpretes, enumerando e discutindo as melhores práticas da AIIC para formação de intérpretes e as evidências da profissionalização no âmbito da formação de intérpretes nos últimos 20 anos.

Palavras-chave: Interpretação de conferências; formação de intérpretes; melhores práticas.

\section{Abstract}

Even though interpreting has been a professional activity for many centuries, we can state that interpreter training was established only in the first half of the $20^{\text {th }}$ century. The goal of this paper is to highlight the influence of the International Association of Conference Interpreters (AIIC) on the history of interpreter training. AIIC's best practices for interpreter training are listed and explained and an argument is made about evidences that show that in the last 20 years interpreter training has become more professional.

Keywords: Conference interpreting; interpreter training; best practices. 